\title{
Research On Technological Utilizing in an Automatic Device for Collecting Rain and Snow in Qinghai Province, China
}

\author{
Mingtao Long ${ }^{1}$, Luyao $\mathrm{Hu}^{3}$, Jiaquan Yang ${ }^{1}$, Yongjun $\mathrm{Hu}^{1}$, Zihan Wang ${ }^{1}$, Liping Zheng ${ }^{1}$, and Beiming Kang ${ }^{1,2^{*}}$ \\ ${ }^{1}$ School of Water Resources and Electric Power, Qinghai University, Xining 810016, China \\ ${ }^{2}$ Key Laboratory of Ecological Protection and High-Quality Development in the Upper Yellow River, Qinghai University, Xining, \\ 810016, China \\ ${ }^{3}$ School of Chemical Engineering and Technology, Qinghai University, Xining 810016, China
}

\begin{abstract}
Based on the climatic conditions in the northwest and the widely used water storage method in the northwest rural areas, we designed a rain and snow collection device, which is realized by an inductor and an "M" collection curtain, which uses the rotation of the motor and the supply of the heating film. Water purification and storage can be obtained through compound grit tanks, biochar adsorption systems, etc. The collected water resources can be integrated with water purification and storage through flood control and antifreeze devices. Real-time senses the changes of water level and water temperature. In this article, a calculation model for the optimal sedimentation effect is also established, which can calculate the minimum scale parameters of the sedimentation tank under different weather conditions, and provide guidance for the construction of the system. In addition, we tested the actual collection capacity of the system, and the results showed that the system has high practical value. At present, there is no a complete and systematic study integrated with it in the Northwest region. This system can alleviate the lack of water resources in some areas to a certain extent, play a positive role in the rural ecological environment and lessen flood
\end{abstract}

\section{Introduction}

China is a serious water shortage country. The per capita freshwater resources are only $1 / 4$ of the world average, and the regional distribution is extremely uneven. Zhao Liangshi et al. ${ }^{[1]}$ pointed out that the water use efficiency of Qinghai Province is only 0.069 and 0.089 with and without considering undesired output. Gao Xincai, Yin Songkui, and others ${ }^{[2]}$ pointed out that under the premise that the total amount of water resources and the scale of water supply remain relatively stable, the key to alleviating the contradiction between the supply and demand of urban water resources is to improve the efficiency of water use. Huang Chunsheng, Hou Xinghua, etc. ${ }^{[3-4]}$ respectively proposed a method based on drainage pipes, pipe network systems, etc., to consider and install precipitation collection devices to collect water resources at the early stage of construction planning and to improve water resources utilization. However, this method has engineering Problems such as large quantity and high investment cost. Precipitation is an important link in the natural water cycle system, and it plays an extremely critical role in regulating and replenishing groundwater and improving and protecting the ecological environment. Xue Wei et al. ${ }^{[5]}$ analyzed the water quality of precipitation in Xinjiang and verified that natural rainfall has an important role as a city. Miscellaneous water, landscape water, and agricultural irrigation water potential. $\mathrm{Li}$ Xiang and others ${ }^{[6]}$ designed an embedded courtyard sprinkler irrigation water-saving controller. The user can access the controller in real-time through the Internet to realize the automatic management of garden sprinkler irrigation and verify the application effect of the controller through application examples. The device is simple to operate and meets the requirements of courtyard irrigation. The realization of water-saving, but the effect of watersaving lies more in the irrigation process, ignoring the collection and reuse of water resources. Based on relevant research data at home and abroad, combined with existing $\mathrm{MCU}$, this paper proposes a rain and snow collection and purification system based on Qinghai.

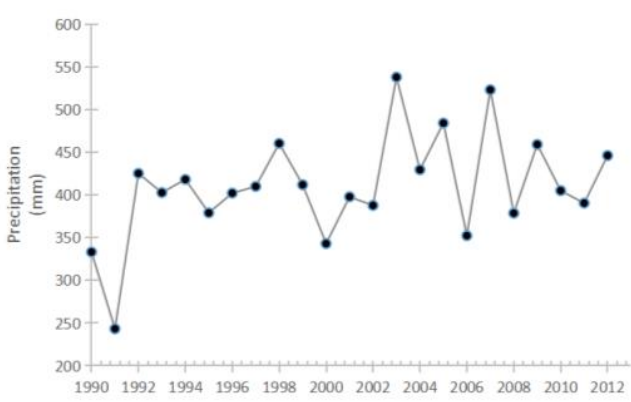

Fig. 1. 30-year precipitation distribution in Xining (19882012) Unit: $\mathrm{mm}$

\footnotetext{
* Corresponding author: Beiming Kang, Kangbeiming1988@163.com

Young and Middle-aged Scientific Research Fund Project of Qinghai University（2020-QGY-13、2018-QGY-9）
} 
The Qinghai region is far away from the ocean. The average annual precipitation is below $400 \mathrm{~mm}$. The uneven distribution of precipitation, shortage of water resources, and the fragile ecological environment have severely restricted the development of the local economy and the improvement of people's living standards. As far as Qinghai is concerned, there is less industrial pollution, and the quality of rainwater and snow water is relatively good. Only a simple purification process can meet the requirements for green water quality in the "Technical Specifications for Construction and Residential Rainwater Utilization Engineering". Therefore, in the northwest region, the collection and purification of rain and snow are of great significance in solving the problem of water shortage, compensating the rural ecological environment, and preventing floods and disasters.

\section{Status Quo Investigation}

\subsection{Survey Content}

To verify the feasibility and practical operability of the system, we took Fanjiaping Village, Putai Township,
Ledu District, Qinghai Province as the survey object. And the water quality of the water in the cellar was investigated. The source of drinking water for Fanjiaping villagers is in Hengshan, Zhongba, 20 kilometers away from the village. There are 10 water supply points in the village, and the villagers need to get drinking water from the water supply points. Due to the terrain and elevation in this area, the tap water supply is unstable and there is often a shortage of water. Residents generally rely on cellars to store water or drive water from the township government or health center 10 kilometers away. Some cellars in the investigation area have been abandoned, but most of them are still in use. Because of the lack of water resources in the region and the massive use of water cellars, we have studied a complete system for rain and snow collection, cellar water storage, and purification in the northwest region, which can greatly improve the happiness of the people in the northwest of water shortage, and at the same time comply with the state. The concept of environmental protection advocated.

\subsection{Survey Results}

Table 1 Investigation table of water cellars in Fanjiaping Village, Ledu County

\begin{tabular}{|c|c|c|c|c|c|c|}
\hline Point & Position & Quantity & Usage & $\begin{array}{l}\text { Water } \\
\text { quality }\end{array}$ & application & Remarks \\
\hline 1 & $\begin{array}{c}\text { Village } \\
\text { committee gate }\end{array}$ & 9 & Deserted & Poor & Null & collective \\
\hline 2 & $\begin{array}{l}200 \mathrm{~m} \text { across } \\
\text { from the village } \\
\text { committee }\end{array}$ & 5 & Using & Good & $\begin{array}{l}\text { Drinking water for } \\
\text { humans and } \\
\text { animals }\end{array}$ & Personal \\
\hline 3 & $\begin{array}{l}\text { Resident's home } \\
\text { opposite the } \\
\text { village committee } \\
1\end{array}$ & 4 & Using & Good & $\begin{array}{l}\text { Drinking water for } \\
\text { humans and } \\
\text { animals }\end{array}$ & Personal \\
\hline 4 & $\begin{array}{l}\text { Behind the } \\
\text { village committee }\end{array}$ & 11 & Deserted & Poor & Null & Collective \\
\hline 5 & $\begin{array}{l}\text { Resident's home } \\
\text { next to the village } \\
\text { committee } 2\end{array}$ & 2 & Using & Good & $\begin{array}{l}\text { Drinking water for } \\
\text { humans and } \\
\text { animals }\end{array}$ & Personal \\
\hline 6 & $\begin{array}{c}\text { Residents behind } \\
\text { the village } \\
\text { committee } 3\end{array}$ & 3 & Using & Good & $\begin{array}{l}\text { Drinking water for } \\
\text { humans and } \\
\text { animals }\end{array}$ & Personal \\
\hline
\end{tabular}

- The use of water cellars is more common in Northwest China, mainly in rural households;

- The quality of the water stored in the cellar can meet the requirements of humans and animals;

- For a long time in the future, the water cellar will not disappear in the countryside.

\section{Design Principles}

\subsection{Design Ideas}

Rainwater in rural areas is mainly collected through roof confluence. This collection method can easily deteriorate the quality of rainwater, cause secondary pollution, and increase the difficulty of rainwater purification. To solve this problem, the team proposed to use an automatically retractable curtain to collect rainwater, maintain good rainwater quality, and reduce the difficulty of purification. The northwestern region has abundant snowfall in winter. To collect snow water and reduce the damage to the house, we installed a heating film in the curtain interlayer to heat the snow to melt it into the water and then collect it. The collected water is filtered through the grit tank to remove impurities, flows into the water cellar for temporary storage, and then passes through the biochar purification device to remove impurities such as heavy metal ions and harmful organics. In addition, the team used the circulating water flow to prevent freezing on the water surface based on the principle of anti-freezing of the reservoir. 


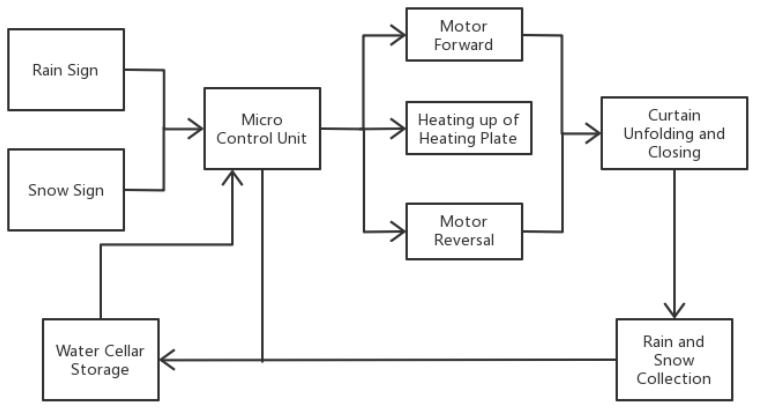

Fig. 2. System workflow

\section{$3.2 \mathrm{MCU}$}

\subsubsection{MCU Principle}

The MCU's high performance, high reliability, low power consumption, low noise, and low cost made us choose MCU as the central controller of the system. The core of the system controller is the AT89S52 single-chip microcomputer, and the monitoring module is a water drop sensor and a water level sensor. The sample motor is a 28BYJ-48 5 volt stepper motor (STEP MOTOR). After the controller is powered on, each device enters the working mode. The water drop sensor monitors the sky climate conditions in real-time and generates data to send to the controller. At the same time, the water level sensor monitors the water level in the water cellar in real-time. When the water drop sensor detects the water resource and sends a signal, the controller will The data of the water level sensor will be read. If the water level sensor detects that the water volume in the cellar has not reached the limit value, the controller will issue a collection command to control the operation of the motor to unfold the curtain and collect rain and snow. After the work is over, that is, when the water drop sensor has not sensed water resources, the controller returns to its original state and the curtain is closed.

\subsubsection{Sensor}

The water drop sensor used has the DO output function, that is, it can directly output 0 or 1 signals, and these two signals can be directly received by the controller without the need to transform analog signals to digital signals. Because this system only needs to monitor the limit value of the water level, the water level sensor is the same as the water drop sensor, and the water level sensor with DO output function is used. The principle is the same as that of the water drop sensor.

\subsection{Structural design}

\subsubsection{Rain and snow collection system}

The device is mainly composed of an "M" type curtain, control system, and power system. The "M" type curtain is composed of two linear guides, brackets, and rain film. It has automatic shrinking and heating functions. It is in a retracted state on sunny days, which can reduce the pollution of the rain shed from the external environment, ensure the quality of rainwater, and reduce the difficulty of purification; yes When it rains, the canopy is opened to collect water; when there is snow, the canopy is opened and the heating plate provides heat to melt the snow and collect it.

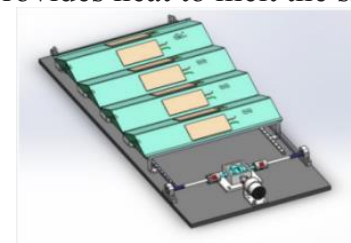

(a)

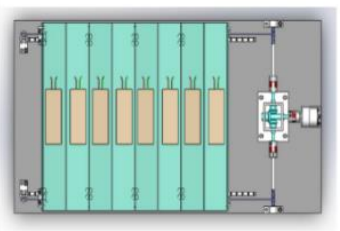

(b)

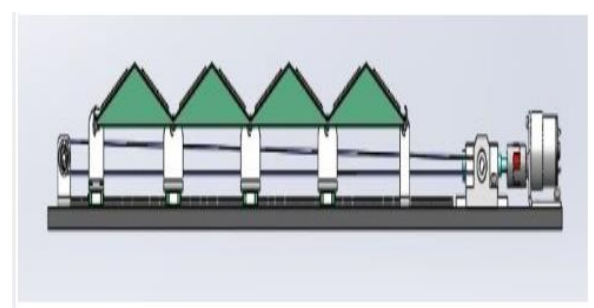

(c)

Fig. 3. Curtain design drawing

\subsubsection{Water cellar purification and storage system}

At present, the main methods for removing pollutants in water cellars ${ }^{[7-8]}$ are ultraviolet light, ultrafiltration, biological slow filtration, an adsorption method, etc. Compared with other methods, the adsorption method has the advantages of simple operation, no need to add a large number of chemical agents, and less energy consumption. In the adsorption method, the adsorption material is the key factor. Numerous data ${ }^{[9-10]}$ indicate that as an adsorbent, biochar has a better effect in the water purification process, and the cost is relatively low; in addition, the degree of carbonization of biochar is relatively low, and the residual hydroxide groups can remove heavy metal ions and harmful Organic matter. The rainwater collected in the northwest has fewer impurities and can reach the standard of use after biochar purification treatment. After the collected rainwater flows out of the water cellar, it flows into the biochar purification device. Biochar can remove fine particles, branches and leaves, and other impurities in the water, and because of its huge specific surface area and more adsorption sites, it can also be removed Substances such as ammonia nitrogen, and phosphorus in the water ${ }^{[11]}$. After the biochar is used for a long time, its purification capacity and adsorption effect will be weakened. Using the principle of backwashing, water is reversed into the device to wash away the impurities accumulated on the surface of the biochar, so that the biochar can restore the purification capacity and adsorption effect. 


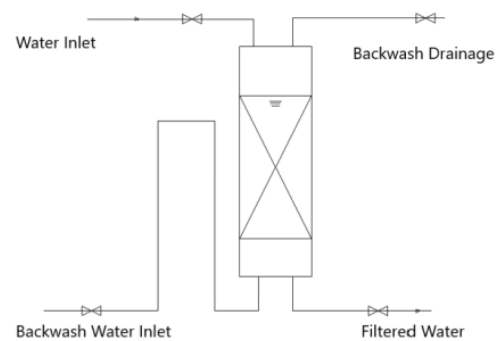

Fig. 4. Schematic diagram of biochar washing and purification

The water after preliminary disinfection passes through the grit tank to filter out large particles, and then enters the water cellar for storage. In the water cellar, there is an independent ultraviolet light lamp. Experiments show that the water cellar equipped with 220, 30 ultraviolet lamps has microorganisms. The reproduction rate is greatly reduced. The water cellar is also equipped with a drainage and antifreeze device, which can stop the water collection in real-time to prevent the water cellar from collecting too much water and causing damage to the water cellar.

\subsection{Calculation Model of Optimal Effect Parameters of Grit Tank}

The purpose of setting up the sedimentation basin is to reduce the sediment content in the rainwater. The principle is to use the water flow rate to decrease when the water cross-section increases and the sediment carrying capacity of the water flow decreases, thereby achieving the purpose of sedimentation of the sediment. The size of the grit tank is designed according to the effect of the horizontal velocity and gravity sinking to the bottom of the pool under the combined action of the horizontal velocity and gravity.

To achieve the strongest sand settlement effect, we have established an optimal effect calculation model. In the pool, a single brick wall is used to build an inclined wall to form a compound sedimentation basin similar to the principle of the labyrinth inclined plate sedimentation tank. Water can also be taken from the side and sand can be discharged.

Let L, B, and $\mathrm{H}$ represent the length, width, and depth of the sedimentation basin respectively, and the theoretical settling time of the designed standard particle size sediment is:

$$
\begin{gathered}
T_{c}=\frac{h}{V_{c}} \\
V_{c}=0.63 D_{c}^{2}(\rho-1)
\end{gathered}
$$

In the formula: is the sedimentation rate of the standard particle size, the unit is; is the standard particle size, the unit is; is the sediment density generally taken; is the working water depth of the sedimentation tank, the unit is.

If the rainwater confluence flow is, the transport speed of the sediment level is:

$$
V_{p}=\frac{Q}{B^{*} H}
$$

The running time of the sediment in the pool can be calculated by the following formula:

$$
T=\frac{L}{V_{D}}
$$

From kinematics, we can see that the combined equations (1) and (4) are:

$$
L=\frac{Q}{B^{*} V_{c}}
$$

According to the existing practical experience, the depth of the pool and the aspect ratio of $2: 1$ is more appropriate. If the value is too small, the width of the tank will increase, which is not conducive to sedimentation and is not economical. Therefore, the size of the sedimentation basin can be designed by the following formula:

$$
H \geq 1(m), B=0.5(L)
$$

From (1) to (6), the scale parameters of the grit tank required for the optimal sedimentation effect can be calculated.

Take heavy rain (rainfall $\geq 16 \mathrm{~mm} / \mathrm{h}$ ) as an example to record the size of the sand basin. Take, then:

$$
\begin{aligned}
& \mathrm{Vc}=0.0024 \mathrm{~m} / \mathrm{s} \\
& \mathrm{Q}=0.0005 \mathrm{~m}^{3} / \mathrm{s}
\end{aligned}
$$

Substituting into equation (5), we get. Therefore, when the rainstorm is the most extreme weather, the minimum scale of the grit tank should be set as: $0.64 \mathrm{~m}$ in length, $0.32 \mathrm{~m}$ in width, and $1 \mathrm{~m}$ in height.

\section{Conclusion}

We believe that the amount of rain and snow collected by this system is closely related to the amount of precipitation. We selected the precipitation in Xining, Qinghai Province in 2012 as the data, set the curtain to be 3 square meters, and carried out the data analysis of the system rainwater collection, as shown in Figure 4. The results showed that only on a 3 square meter curtain, the system collected 1338.3 liters of rainwater in 2013, and the average daily collection volume was about 3.67 liters.

To test the system's ability to collect water resources, we measured the actual rainwater collection volume of the system throughout 2020, as shown in Figure 5. The results found that the ideal precipitation collection volume in 2020 is expected to be 1336.5 liters, and the system collects The precipitation is 1296.3 liters, and the average daily collected precipitation is 3.54 liters. The actual collection rate of the system has reached $96.99 \%$, which is of high practical value. 


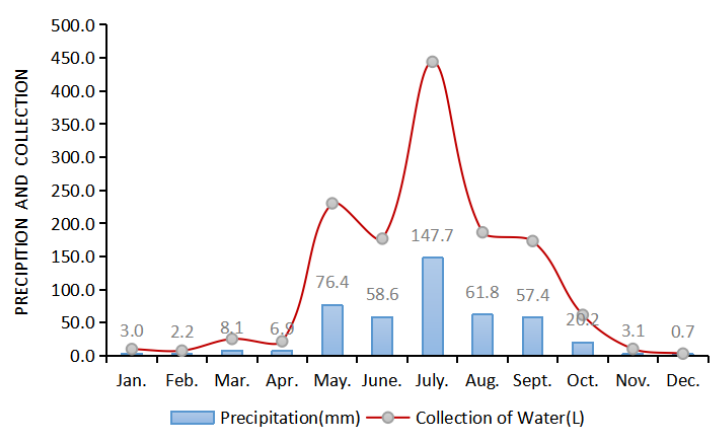

Fig. 5. (2012) Relation diagram of precipitation and unit water collection

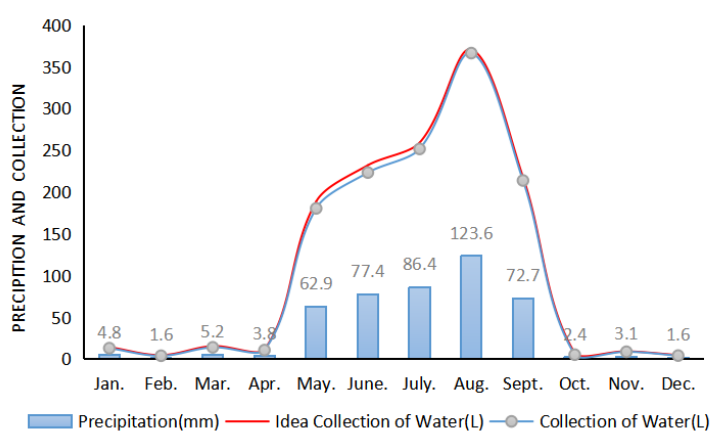

Fig. 6. Test chart of system precipitation collection (2020)

At present, there is a shortage of water resources in Northwest my country, and the demand for water resources is large. The rain and snow collection and utilization system can greatly alleviate the consumption of water resources such as domestic water and irrigation water, and can also reduce drought and flood disasters, ecological balance damage, etc. environmental issues. The practice of recycling rainwater and snow water at home and abroad has proved its great value. We believe that the research and development of this system can bring actual ecological and economic benefits to the northwest region, among which the ecological benefits are in line with the country's vigorously advocated " Green water and green mountains are the concept of "The Golden Mountains and Silver Mountains".

\section{Acknowledgment}

This research is funded by the Innovation and Entrepreneurship Training Program of Qinghai University in 2020 (2020-QX-31) and Young and Middle-aged Scientific Research Fund Project of Qinghai University（2020-QGY-13、2018-QGY-9）. The authors gratefully acknowledge these supports.

\section{References}

1. Zhao Liangshi, Sun Caizhi, Zheng Defeng. Measurement of water resources utilization efficiency and spatial spillover effects between provinces in China[J]. Acta Geographica Sinica, 2014, 69(01): 121-133.
2. Gao Xincai, Yin Songkui. Analysis on the Spatiotemporal Evolution and Club Convergence of Urban Water Resources Utilization Efficiency in Northwest China[J/OL]. Jingwei:1-11[2021-03-30].

3. Huang Chunsheng, Guo Jiandong, Wang Limei. Construction technology of project precipitation and rainwater collection and utilization[J]. Tianjin Construction Science and Technology, 2012, 22(05): 12-13.

4. Hou Xinghua, Li Jian, He Fei. Research on the Collection and Utilization System of Precipitation in a University Campus[J]. Building Energy Efficiency, 2016, 44(12): 76-79.

5. Xue Wei, Xu Feng, Li Song, Wang Lei, Liu Ziyang, Tian Ao, Yang Guochao. Discussion on the utilization of precipitation resources on the campus of Shihezi University[J]. Environmental Sanitation Engineering, 2015, 23(06): 42-44.

6. Li Xiang, Liang Liping. Research on the embedded design of courtyard sprinkler irrigation watersaving controller[J]. Environmental Science and Management, 2018, 43(08): 55-58.

7. Zhang Shihua. Comparative analysis of optimization results of three common water cellar structures [J] . Anhui Agricultural Sciences, 2018, 46(20):186-190.

8. Chen Zaiming, Chen Baoliang, Zhou Dandan, Structural characteristics of rice straw biochar and its adsorption performance for organic pollutants[J]. Acta Scientiae Circumstantiae, 2013, 33(1): 9-19.

9. Wu Qiong. Summary of the research progress of biochar for water treatment $[\mathrm{J}]$. Gelatin Science and Technology, 2015, 35(1): 11-16.

10. Xia Guangjie. Study on the adsorption behavior and bioavailability of heavy metals under the influence of biomass carbon [D]. Zhejiang University of Technology, 2014.

11. Liu Jianguang, Zhang Xiaojian, Wang Zhansheng. Biological activated carbon filter for treatment of high ammonia nitrogen raw water [J]. China Water \& Wastewater, 2003(12): 61-64 